\title{
Unresectable Carcinoid Tumor
}

National Cancer Institute

\section{Source}

National Cancer Institute. Unresectable Carcinoid Tumor. NCI Thesaurus. Code C153080.

Carcinoid tumor that is not amenable to surgical resection. 